\title{
ANALISIS MATERIAL REQUIREMENT PLANNING PRODUK BODY SCRUB POWDER PADA CV. DENARA DUTA MANDIRI
}

\author{
Shinta Monica ${ }^{1}$ \\ Putu Yudi Setiawan ${ }^{2}$ \\ ${ }^{1,2}$ Fakultas Ekonomi dan Bisnis Universitas Udayana (Unud), Bali, Indonesia \\ e-mail:smonica093@gmail.com
}

\begin{abstract}
ABSTRAK
Manajemen persediaan yang tidak tepat dapat mengakibatkan terjadinya kekurangan ataupun kelebihan persediaan bahan baku. Salah satu konsep yang dapat digunakan untuk melakukan perencanaan dan pengendalian bahan baku yaitu sistem Material Requirement Planning (MRP). Penelitian ini bertujuan unntuk mengetahui jumlah kebutuhan bersih, ukuran besarnya pemesanan, waktu pemesanan, dan metode yang menghasilkan biaya terendah untuk masing-masing bahan baku. Teknik analisis data yang dilakukan yaitu pembuatan jadwal induk produksi, penentuan kebutuhan bersih, penentuan ukuran lot (metode lot for lot dan part period balancing), penentuan lot sizing yang optimal dan penentuan waktu untuk memesan bahan baku atau proses pembuatan tabel MRP. Hasil penelitian menunjukkan bahwa peramalan trend projection memiliki kesalahan peramalan terkecil dengan hasil peramalan $82 \mathrm{~kg}$. Metode lot sizing yang terbaik adalah part period balancing yang menghasilkan total biaya persediaan Rp Rp 338.911,24 dimana total biaya tersebut lebih rendah, jika dibandingkan dengan total biaya persediaan metode lot for lot yang sebesar Rp 795.000.

Kata Kunci: material requirement planning (mrp), forecasting, lot sizing, lot for lot, part period balancing
\end{abstract}

\begin{abstract}
Improper Inventory management can results in deficiency or excess inventory of raw materials. One concept that can be used to plan and control raw materials is the Material Requirement Planning (MRP) system. The purpose of this study is to find out the number of net requirements, size of order, time of order, and methods that produce the lowest cost for each raw materialData analysis techniques are carried out, namely making production master schedules, determining net requirements, determining lot size (lot for lot method and part period balancing), determining optimal lot sizing and determining the time of ordering raw materials or making MRP tables. The results showed that trend projection forecasting had the smallest forecasting error with $82 \mathrm{~kg}$ forecasting results. Determination of order size or lot sizing obtained by the best lot sizing method is part period balancing which results in a total inventory cost of Rp. 338.911 .24 where the total cost is lower, compared to the total inventory cost lot for lot method which is Rp. 795.000.

Keywords: material requirement planning ( $m r p)$, forecasting, lot sizing, lot for lot, part period balancing
\end{abstract}




\section{PENDAHULUAN}

Perkembangan teknologi yang semakin canggih maka semakin ketat juga persaingan dalam industri manufaktur. Persaingan yang semakin ketat ini menuntut perusahaan untuk dapat memenangkan persaingan dan meraih pangsa pasar yang lebih luas. Dalam lingkungan pemasaran saat ini, pangsa pasar, kinerja tinggi dapat dicapai dengan memberikan produk dan layanan yang dihasilkan oleh perusahaan dalam waktu, biaya minimum, kuantitas pesanan optimal, kondisi layanan terbaik dan dalam periode waktu yang paling tepat(Torunogluet al., 2017).Pada perusahaan manufaktur kegiatan produksi dan persediaan yang tepat sangat menentukan kelancaran produksi.

Secara sengaja atau tidak setiap perusahaan manufaktur akan memiliki persediaan karena kegiatan perusahaan manufaktur yaitu menjalankan proses produksi yang mengolah bahan baku menjadi produk yang mempunyai nilai tambah. Perusahaan manufaktur memiliki persediaan yang dapat berupa bahan baku atau material, komponen produk, barang setengah jadi, dan barang jadi. Jumlah persediaan akan mempengaruhi proses produksi yang berdampak pada efisiensi dan keefektivan setiap perusahaan. Fajar S \& Wiwi, (2014)menyatakan demi menciptakan sistem produksi yang efisien maka dibutuhkan perencanaan produksi yang baik dengan ditunjang adanya perencanaan pengadaan material atau bahan baku yang baik pula.Persediaan yang terlalu tinggi dapat menimbulkan kemungkinan kerugian yang terjadi akibat kerusakan, keusangan, penurunan kualitas persediaan serta memperbesar biaya pemeliharaan dan penyimpanan (Riyanto, 2012:69). Demikian pula apabila terjadi kekurangan menimbulkan biaya 
kekurangan persediaan. Melakukan perencanaan bahan baku merupakan cara yang efektif untuk mendapatkan manajemen persediaan yang baik(Jonsson \& Mattsson, 2016).

Pada kegiatan perencanaan dan pengendalian bahan untuk menghindari berbagai permasalahan bahan baku dan mendukung koordinasi kegiatan produksi diperlukan suatu sistem perencanaan. Konsep dalam perencanaan dan pengendalian persediaan salah satunya yaitu sistem Material Requirement Planning (MRP). Material Requirement Planning (MRP) bertujuan untuk efisiensi bahan baku, komponen, dan sub-assemblies dengan jumlah dan waktu yang tepat dalam penjadwalan kebutuhan produksi (Olaore \& Olayanju, 2013). Manajer persediaan dan produksi juga mendapat informasi yang sesuai dengan adanya sistem MRP(Panizzolo \& Garengo, 2013).Perusahaan manufaktur dalam menentukan kapan dan jumlah bahan yang dibeli serta diproses berdasarkan peramalan, analisis pesanan penjualan, pesanan produksi, dan persediaan yang ada dapat dibantu dengan adanya sistem MRP (Gharakhani, 2011).

Menurut Heizer dan Render (Haizer \& Barry, 2015:678), Material Requirement Planning (MRP) adalah suatu teknik permintaan dependen yang menggunakan daftar bahan, permintaan, penerimaan yang diharapkan, persediaan, dan jadwal produksi induk untuk menentukan kebutuhan bahan material. MRP memiliki dampak signifikan dalam pengurangan biaya produksi, penghematan waktu, pengadaan, pelayanan, dan memperbaiki waktu pengiriman yang sesuai dalam melakukan perencanaan dan penjadwalan sistem produksi (Dineshet al., 2014; Imetieg \& Lutovac, 2015). Bentuk yang paling sederhana sistem 
MRPterdiri dari tiga komponen dasar: jadwal produksi induk (MPS); file billofmaterial (BOM) dari item akhir; dan file status persediaan berbagai bahan, komponen, bagian, sub-rakitan dan produk akhir(Sarkaret al., 2013).

Penelitian empiris yang mendukung diterapkannya metode lot-sizing yang merupakan proses dari MRP dapat menurunkan biaya persediaan, terjaminnya ketersediaan bahan saat dibutuhkan serta meminimalkan persediaan (Adeelet al., 2012; Aristiyanto dkk., 2016; Ayu dkk., 2013; Chandradevi \& Puspitasari, 2016; Iasya \& Handayati, 2015; Limbonget al., 2013; Sungkono \& Sulistiyowati, 2016; Suparno, 2017; Theresia \& Salomon, 2015; Wahyuni \& Syaichu, 2015). Penentuan ukuran pemesanan (lot sizing) pada sistem MRP harus sesuai dengan statis atau dinamisnya data permintaan bila data permintaan dinamis maka lot sizing yang digunakan model dinamis dan bila statis yang digunakan model lot sizing yang statis (Hafiz \& Parveen, 2010). Penggunaan MRP juga menunjukkan perbaikan dengan menurunnya biaya persediaan, efisiensi, dan ketepatan informasi yang lebih akurat (Santinet al., 2015). Hasil penelitian dari Anggriana, (2015)mengemukakan pelanggantidak perlu menunggu waktu lama untuk pengadaan bahan baku sehingga waktu pengirimandapat dihemat dengan penggunaan sistem MRP yang didukung penelitian (Chandrajuet al., 2012)menyatakan dengan menggunakan sistem MRP maka produk dipesan dan diterima dalam periode yang aman. Maka dapat dikatakan bahwa MRP dapat membantu industri atau perusahaan dalam meningkatkan efektifitas dan efisiensi produksi. 
Industri-industri yang ada di Bali terus berkembang karena Bali merupakan salah satu tujuan wisata yang paling banyak dikunjung. Daya tarik lain saat berwisata yang dilakukan oleh wisatawan yaitu menikmati SPA. Adanya minat wisatawan terhadap SPA berdampak pada banyaknya industri produk-produk SPA yang ada di Bali. Menjamurnya perusahaan-perusahaan yang bergerak dibidang produk SPA ini menjadikan persaingan semakin ketat berebut pasar. Persaingan yang ketat ini semakin lama mengakibatkan permintaan yang tidak sebanding hingga terjadi penurunan permintaan. Salah satu perusahaan yang mengalami penurunan jumlah permintaan produk SPA yaitu CV. Denara Duta Mandiri.

Tabel 1.

Data Permintaan Body Scrub Powder di CV. Denara Duta Mandiri

\begin{tabular}{cc}
\hline Bulan (Tahun) & Jumlah \\
\hline Oktober (2017) & $44 \mathrm{~kg}$ \\
November (2017) & $65 \mathrm{~kg}$ \\
Desember (2017) & $33 \mathrm{~kg}$ \\
Januari (2018) & $38 \mathrm{~kg}$ \\
Februari (2018) & $59 \mathrm{~kg}$ \\
Maret (2018) & $72 \mathrm{~kg}$ \\
April (2018) & $76 \mathrm{~kg}$ \\
Mei (2018) & $110 \mathrm{~kg}$ \\
Juni (2018) & $81 \mathrm{~kg}$ \\
Juli (2018) & $70 \mathrm{~kg}$ \\
Agustus (2018) & $61 \mathrm{~kg}$ \\
September (2018) & $60 \mathrm{~kg}$ \\
\hline
\end{tabular}

Sumber :CV. Denara Duta Mandiri,2018

Tabel 1 menunjukkan bahwa terjadinya penurunan jumlah permintaan body scrub powder sejak juni 2018 di CV. Dendara Duta Mandiri. CV. Denara Duta Mandiri adalah perusahaan yang bergerak dibidang kosmetik dan SPA yang berlokasi di Padangsambian, Denpasar-Bali. CV. Denara Duta Mandiri memproduksi berbagai produk SPA mulai dari berbagai macam lulur, body lotion, massage cream, garam mandi dan produk SPA lainnya. Body scrub powder 
adalah lulur bubuk yang digunakan untuk membantu mengangkat kotoran dan debu yang menempel pada kulit maupun sel-sel kulit mati. Body scrub powder dapat digunakan sendiri oleh para konsumen maupun digunakan oleh tempattempat SPA untuk keperluan SPA. Body scrub powder memiliki berbagai varian aroma dan varian kemasan berukuran 100 gram dan $1 \mathrm{~kg}$.

Proses produksi dari body scrub powder dapat dilakukan setiap hari dalam sebulan (kecuali hari minggu). Rata-rata untuk perharinya CV. Denara Duta Mandiri dapat memproduksi body scrub powder sebanyak $5 \mathrm{~kg}$. CV. Denara Duta Mandiri selalu memiliki persediaan produk jadi dan bahan baku untuk mengantisipasi adanya banyak pesanan. Namun, beberapa bulan terakhir ini terjadi penurunan penjualan salah satunya produk body scrub powder. Terjadinya penurunan penjualan serta terdapatnya persediaan produk jadi dan bahan baku yang apabila jumlahnya lebih besar dibandingkan dengan permintaan/kebutuhan maka dapat mengakibatkan perusahaan mengalami kelebihan persediaan dan menimbulkan biaya persediaan yang lebih tinggi.

Berkaitan dengan masalah yang terjadi pada perusahaan CV. Denara Duta Mandiri yaitu manajemen persediaan yang tanpa metode maka perlu dicarikan sebuah cara atau metode yang dapat mengatasin permasalahan tersebut. Sistem Material Requirement Planning (MRP) yang akan diterapkan pada CV. Denara Duta Mandiri diharapkan dalam perencanaan produksi, pemenuhan kebutuhan dapat dilaksanakan secara tepat, dan penetapan biaya persediaan dapat ditetapkan seminimal mungkin. 
Berdasarkan latar belakang di atas, maka rumusan masalah dalam penelitian ini yaitu: Apakah penentuan jumlah kebutuhan bersih, besarnya pesanan, dan kapan waktu dalam melakukan perencana pemesanan untuk bahan baku produk body scrub powder $1 \mathrm{~kg}$ yang efisien serta metode lot sizing manakah yang menghasilkan biaya terendah untuk produk body scrub powder $1 \mathrm{~kg}$ di CV. Denara Duta Mandiri. Tujuan penelitian ini yaitu: mengetahui serta menentukan jumlah kebutuhan bersih, besarnya pesanan yang optimal dan waktu yang tepat dalam melakukan perencana pemesanan untuk setiap bahan baku produk body scrub powder $1 \mathrm{~kg}$ di CV. Denara Duta Mandiri, serta mengetahui serta menentukan metode lot sizing yang menghasilkan biaya terendah untuk produk body scrub powder $1 \mathrm{~kg}$ di CV. Denara Duta Mandiri.

Menurut Krajewskiet al.(2016:339), persediaan adalah material yang digunakan untuk memuaskan permintaan konsumen atau untuk mendukung kegiatan produksi jasa atau barang. Menurut Rangkuti (2007:7), persediaan secara terus menerus didapatkan, diubah, lalu dijual kembali hal ini menjadikan persediaan salah satu unsur yang paling aktif dalam kegiatan operasi perusahaan. Menurut Haizer \& Barry (2015:553),persediaan adalah salah satu asset termahal dari banyak perusahaan dan persediaan mewakili sebanyak 50\% investasi dari keseluruhan modal.

Menurut Haizer \& Barry (2015:553), persediaan adalah salah satu asset termahal dari banyak perusahaan dan persediaan mewakili sebanyak 50\% investasi dari keseluruhan modal. Telah lama disadari oleh manajer operasi di seluruh dunia bahwa manajemen persediaan yang baik sangatlah penting. Di satu 
sisi, dengan mengurangi persediaan maka perusahaan dapat mengurangi biaya. Di sisi lain, bila barang tidak tersedia maka produksi dapat berhenti dan pelanggan menjadi tidak puas. Mentukan keseimbangan antara pelayanan pelanggan dan investasi merupakan tujuan manajemen persediaan.

Menurut Subagyo dkk.(2013:206), fungsi utama dari persediaan adalah menyimpan bahan mentah/barang jadi dari waktu ke waktu guna melayani kebutuhan. Menurut Heizer dan Render (2015:553), fungsi persediaan yang dapat menambah fleksibilitas perusahaan operasi perusahaan dibagi menjadi empat santara lain: untuk antisipasi dalam memenuhi permintaan pelanggan dengan memberikan berbagai pilihan barang, untuk memisahkan proses produksi menjadi beberapa tahapan, untuk mengambil keuntungan dari menurunnya biaya pengiriman barang dengan pembelian dalam jumlah besar.untuk menghindari kenaikan harga dan inflasi. Menurut Handoko (2000:335), persediaan memiliki beberapa fungsi yaitu decoupling atau persediaan untuk mengantisipasi fluktuasi permintaan yang tidak dapat diramalkan, economic lot sizing yang merupakan penghematan karena pembelian dengan lot tertentu dan antisipation atau persediaan antisipasi perubahan musim untuk memperlancar produksi.

Menurut Assauri (2008:240), klasifikasi persediaan berdasarkan jenis yaitu: persediaan bahan baku, persediaan bagian produk atau parts yang dibeli, persediaan bahan-bahan pembantu atau supplies stock, persediaan barang setengah jadi atau barang dalam proses, dan persediaan barang jadi. Heizer dan Render (2015:554), menyatakan empat jenis persediaan yang harus dipelihara perusahaan yaitu: persediaan barang mentah, persediaan barang dalam proses, MRO 
Shinta Monica dan Putu Yudi Setiawan, Analisis Material Requirement...

(maintenance/repair/operating) atau persediaan yang disediakan untuk perlengkapan pemeliharaan/perbaikan/operasi, dan persediaan barang jadi. Pada persediaan terdapat biaya yang ditimbulkan antara lain biaya penyimpanan, biaya pemesanan, dan biaya pemasangan sedangkan, menurut Subagyo dkk. (2013:207) terdapat 3 kelompok utama biaya antara lain: (1) ordering dan procurement cost yang merupakan total biaya pengadaan dan pemesanan bahan hingga bahan siap untuk dipergunakan atau diproses lebih lanjut, (2) holding cost atau carrying cost adalah biaya yang timbul akibat perusahaan menyimpan persediaan, dan (3) shortage cost merupakan biaya yang terjadi bila permintaan pada barang yang kebetulan tidak tersedia di gudang.

Menurut Kamarul (2009:7), dalam manajemen persediaan terdapat dua jenis model utama yaitu: persediaan independent dan persediaan dependent. Model persediaan independent adalah persediaan yang penentuan besar pesanan pembelian bahan/barang bersifat bebas, umumnya digunakandalam pembelian persediaan yang memiliki permintaan secara berkelanjutan dari waktu ke waktu dan bersifat tetap/konstan. Pada persediaan independent pembelian dilakukan tanpa mempertibangkan dari penggunaan produk akhirnya sedangkan,model persediaan dependen merupakan model persediaan yang penentuan besar pesanan pembelian atau penyediaan bahan/barang sangat tergantung padahasil akhir produk yang ingin dihasilkan dalam periode produksi tertentu. Produk akhir yang diproduksi jumlahnya tergantung dengan jumlah permintaan konsumen. Permintaan konsumen jumlahnya bersifat independent namun, suku cadang atau 
komponen dari produk tersebut bersifat dependent terhadap jumlah akhir produk yang harus dihasilkan.

MenurutKumar \& Suresh (2008:92), pengendalian persediaan adalah pendekatan terencana dalam penentuan apa yang dipesan, waktu memesan dan jumlah yang dipesan serta berapa banyak persediaan agar biaya yang terkait dengan pembelian dan penyimpanan optimal tanpa mengganggu produksi dan penjualan. Menurut Joko (2004:353), pengendalian persediaan merupakan sebuah struktur untuk melakukan pengawasan terhadap tingkat persediaan dengan cara menentukan seberapa besar jumlah barang yang akan dipesan (the level of replenishment) dan kapan waktu pemesanannya.

Menurut Nasution \& Prasetyawan (2008:29), peramalan adalah proses untuk memperkirakan jumlah kebutuhan diwaktu mendatang seperti kebutuhan dalam ukuran kuantitas, kualitas, waktu dan lokasi yang diperlukan dalam rangka memenuhi permintaan barang ataupun jasa. Metode peramalan yang digunakan dalam penelitian ini adalah time series (Heizer dan Render, 2015:120-136) berikut :peramalan moving average menggunakan sejumlah nilai data aktual historis untuk menghasilkan peramalan. Moving average bermanfaat jika dapat diasumsikan permintaan pasar akan tetap kokoh secara wajar selama bertahuntahun. Peramalan exponential smoothing adalah metode peramalan yang menggunakan sedikit catatan yang mempertahankan data masa sebelumnya dan mudah untuk digunakan secara wajar. Trend projection atau proyeksi kecenderungan adalah teknik yang menyesuaikan garis kecenderungan dengan rangkaian poin data historis dan kemudian, memproyeksikan kemiringan garis ke 
Shinta Monica dan Putu Yudi Setiawan, Analisis Material Requirement...

dalam peramalan masa mendatang atau dalam jangka menengah hingga jangka panjang. Ada beberapa teknik dalam model trend ini namun dalam memutuskan untuk mengembangkan garis kecenderungan linear metode statistik yang tepat dapat menerapakan metode kuadrat terkecil (least square method).

Hasil peramalan dari ketiga metode peramalan tersebut kemudian dilakukan perhitungan kesalahan peramalan. Menurut Kusuma (2009:39), analisis kesalahan peramalan yang biasanya digunakan adalah : deviasi rata-rata yang absolut (meanabsolute deviation-MAD) nilai ini dihitung dengan cara mendapatkan jumlah nilai absolute kesalahan peramalan individual (deviasi) dan membaginya dengan jumlah periode data (n), MAPE (Mean Absolute Percent Error) menghitung sebagai perbedaan rata-rata yang absolut antara nilai yang diramalkan dengan aktualnya, dan MSE yang merupakan rata-rata selisih kuadrat antara nilai yang diramalkan dan yang diamati.Hasil peramalan dengan MAD, MAPE, dan MSE terkecil atau kesalahan peramalan terkecil (standart error of the estimate) digunakan sebagai bahan untuk dasar pembuatan Jadwal Induk Produksi untuk model Material Requirement Planning (MPR).

Menurut Herjanto (2008:275), perencanaan kebutuhan bahan baku (MRP) adalah suatu konsep dalam manajemen produksi yang membahas cara yang tepat dalam perencanaan kebutuhan barang dalam proses produksi. Menurut Kumar dan Suresh (2008:120), tujuan dari Material Requirement Planning (MRP) adalah sebagai berikut: pengurangan persediaan, pengurangan waktu ancang (lead time), komitmen pengiriman yang realistis dan peningkatan efisiensi. 
Menurut Kusuma (2009:177-180),terdapat empat langkah dalam Material Requirement Planningyaitu :netting atau penentuan kebutuhan bersih, lotting atau penentuan besar pesanan, offsetting atau penentuan waktu yang tepat guna melakukan pemesanan dan explosion.Menurut Kumar dan Suresh (2008:120), tujuan dari MRP adalah sebagai berikut: pengurangan persediaan, pengurangan waktu ancang, komitmen pengiriman yang realistis dan peningkatan efisiensi sedangkan, menurut Heizer dan Render (2005:160), beberapa manfaat MRP yaitu: respon yang lebih baik bagi pesanan pelanggan karena jadwal yang terus menerus diperbaiki, respon yang lebih cepat terhadap perubahan pasar, pemanfaatan fasilitas dan tenaga kerja yang terus ditingkatkan, dan tingkat persediaan yang berkurang.

Menurut Kusuma (2009:173), ada empat masukkan untuk MRP yaitu: jadwal induk produksi, struktur produk dan bill of materials, data persediaan, dan waktu ancang. Menurut Davis \& Haineke (2005:550), dari proses MRP dihasilkan dua macam output MRP yaitu: primary report yang termasuk diantaranya planned order, order release notice, changes in due dates, dan cancellations or suspension kemudian secondary report yang termasuk dalam laporan ini antaranya planning report, performance report, dan exception report.

\section{METODE PENELITIAN}

Desain penelitian ini adalah penelitian dengan pendekatan kuantitatif. Penelitian ini dimaksudkan untuk mendapatkan bagaimana penerapan sistem MRP yang akan dilakukan di CV. Denara Duta Mandiri pada produk body scrub powder $1 \mathrm{~kg}$ dengan empat langkah dasar MRP yaitu netting, lotting, offsetting, 
dan explosion untuk mengetahui jumlah kebutuhan, besar pesanan, serta waktu penesanan bahan baku dan penentuan biaya persediaan yang seminimal mingkin. Objek dalam penelitian ini adalah perencanaan dan pegendalian bahan baku produk body scrub powder. Variabel dalam penelitian ini adalah daftar material, jadwal induk produksi, daftar persediaan, netting, lotting, offsetting. Jenis data yang digunakan dalam penelitian ini adalah data kuantitatif dan data kualitatif. Pada penelitian ini data kuantitatif berupa data yang terkait dengan persediaan antara lain data penjualan produk,lead time,bill of material, data aktual persediaan, dan biaya-biaya persediaan sedangkan, data kualitatif berupa struktur produk dan jenis bahan baku yang digunakan yaitu tepung gandum, tepung beras, scrub, ekstrak, parfum, methylparaben, propylparaben, plastik, dan label.

Data yang digunakan adalah data primer dalam penelitian ini diperoleh melalui pengukuran variable-variabel yang terkait dengan penelitian yaitu struktur produk, bill of material (BOM), dan biaya-biaya persediaan serta data sekunder yaitu data-data dokumentasi perusahaan meliputi data penjualan, data aktual persediaan, lead time, dan jumlah bahan baku setiap produksi. Metode pengumpulan data yang dilakukan dengan metode wawancara dan observasi.

Teknik analisis data yang dilakukan dalam penelitian ini adalah teknik analisis kuantitatif yang secara sistematis membahas dengan tahapan sebagai berikut: Tahapan pertama membuat jadwal induk produksi yang berdasarkan hasil peramalan dengan data permintaan atau penjualan perusahaan. peramalan dilakukan dengan tiga metode yaitu moving average, exponential smoothing dan trend projection. 
Peramalan moving average menggunakan sejumlah nilai data aktual historis untuk menghasilkan peramalan. Secara matematis, moving average yang sederhana (yang berfungsi sebagai estimasi permintaan periode berikutnya) dicerminkan dengan hal berikut.

$M$

A

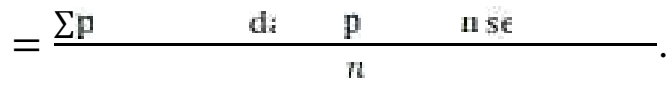

Peramalan exponential smoothing adalah metode peramalan yang menggunakan sangat sedikit catatan yang mempertahankan data masa sebelumnya dan mudah untuk digunakan secara wajar. Formula exponential smoothing secara sistematis sebagai berikut.

$$
F_{t}=F_{t-1}+\alpha\left(\mathrm{A}_{t-1}-F_{t-1}\right)
$$

Peramalan trend projection menggunakan metode kuadrat terkecil dengan persamaan dapat digambarkan sebagai berikut.

$\hat{\mathrm{y}}=a+b x$

Hasil peramalan permintaan menggunakan teknik moving average, exponential smoothing dan least square method, kemudian akan dipilih teknik dengan kesalahan peramalan terkecil (standart error of the estimate). Menurut Kusuma (2009:39), analisis kesalahan peramalan yang digunakan adalah Mean Absolute Deviation (MAD), Mean Absolute Percent Error (MAPE) dan Mean Square Error (MSE). Teknik peramalan dengan kesalahan peramalan terkecil hasilnya akan digunakan sebagai bahan untuk pembuatan jadwal induk produksi pada tahapan proses perhitungan MRP.

Setelah dilakukan peramalan dan diketahui jadwal induk produksi dari hasil peramalan tersebut kemudian dilakukan pengelolaan dan analisis data sistem 
Shinta Monica dan Putu Yudi Setiawan, Analisis Material Requirement...

MRP. Penerapan langkah-langkahnya yaitu: pertama dilakukan netting yang merupakan proses perhitungan untuk nenentukan jumlah kebutuhan bersih yang besarnya adalah selisih antara kebutuhan kotor dengan persediaan ditangan (yang ada dalam persediaan dan yang sedang dipesan). Perhitungan kebutuhan bersih (netting) berikut caranya.

$\mathrm{NRi}=\mathrm{GRi}-\mathrm{Sri}-$ Ohi dengan $\mathrm{NR}=0$ jika GR $-\mathrm{SR}-\mathrm{OH}<0$.

Kedua dilakukan lottinguntuk mengetahui jumlah pesanan optimal untuk setiap bahan baku berdasarkan kebutuhan bersih. Proses lotting merupakan penentuan jumlah komponen atau item yang harus dipesan/disediakan. Metode lot sizing yang digunakan dalam penelitian ini yaitu metode Lot For Lot (LFL) dan Part Period Balancing (PPB).

Teknik lot for lot bertujuan untuk meminimumkan ongkos simpan, sehingga dengan Teknik ini ongkos simpan menjadi nol (Khairani, 2013:105).

$\mathrm{LFL}=[$ kebutuhan total per periode $t]-[$ taksiran sediaan pada akhir periode $t$ 1..(5)

Part Period Balancing (PPB) merupakan pendekatan yang lebih dinamis dengan menyeimbangkan biaya pemesanan dan penyimpanan. PPB menggunakan informasi tambahan dengan mengubah ukuran lot untuk menggambarkan kebutuhan ukuran lot berikutnya di masa datang. Kebutuhan diakumulasikan periode demi periode sampai mendekati nilai (Economic Part Period - EPP). Akumulasi persediaan yang mendekati nilai EPP itu merupakan ukuran lot yang dapat memperkecil biaya persediaan (Herjanto, 1999). Penyeimbang sebagian periode membuat suatu periode ekonomis (Economic Part Period - EPP), yang 
merupakan perbandingan biaya setup dengan biaya penyimpanan. EPP dapat dihitung dengan rumus berikut(Haizer \& Barry, 2005):

$\mathrm{EPP}=\frac{s}{H}$

di mana $\mathrm{S}=$ biaya pemesanan per pesanan

$\mathrm{H}=$ biaya penyimpanan per unit per periode

Tahap ketiga yaitu dilakukan offsettinguntuk menentukan waktu yang tepat melakukan rencana pemesanan untuk memenuhi tingkat kebutuhan bersih. Rencana pemesanan didapatkan dengan cara waktu saat material yang dibutuhkan dikurangi dengan lead time. Langkah terakhir offsetting ini sama dengan proses pembuatan tabel MRP.

\section{HASIL PENELITIAN DAN PEMBAHASAN}

Berdasarkan data penjualan sebelumnya kemudian dilakukan peramalan untuk bulan Oktober 2018. Perhitungan peramalan dilakukan dengan menggunakan bantuan softwarePOMQM for Windows Version 5.2. Teknik peramalan yang digunakan adalah Moving Average, Exponential Smoothing, dan Trend Projection. Berikut ini adalah tabel yang menunjukkan perbandingan nilai MAD, MSE, dan MAPE dari hasilketiga metode peramalan permintaan.

\section{Tabel 2.}

Perbandingan Nilai MAD, MSE, dan MAPE Metode Moving Average, Exponential Smoothing dan Trend Projection

\begin{tabular}{lccc}
\hline Metode & MAD & MSE & MAPE \\
\hline Moving Average & 19,22 & 482,14 & $27,16 \%$ \\
Exponential Smoothing & 18,04 & 528,24 & $26,04 \%$ \\
Trend Projection & 14,16 & 308,14 & $24,1 \%$ \\
\hline
\end{tabular}

Sumber : Data diolah, 2018

Tabel 2 menunjukkan bahwa permintaan bulan Oktober 2018 dengan metode trend projection adalah lebih baik dibandingkan dengan metode moving 
Shinta Monica dan Putu Yudi Setiawan, Analisis Material Requirement...

average dan exponential smoothing, karena memiliki kesalahan peramalan terkecil yang ditunjukkan dengan nilai MAD, MSE, dan MAPE. Hasil peramalan bulan Oktober 2018 menggunakan metode trend projection disajikan dalam tabel berikut.

Peramalan permintaan body scrub powder $1 \mathrm{~kg}$ pada bulan Oktober 2018 yang didapatkan dengan menggunakan trend projection dengan metode least square. Data peramalan tersebut kemudian menjadi bahan pembuat Jadwal Induk Produksi (JIP). Produksi body scrub powder yang ada pada perusahaan dengan make to stock dan pesanan. Namun, data yang didapat saat ini tidak terdapat pesanan jadi, JIP dibuat hanya berdasarkan peramalan dengan besar JIP $82 \mathrm{~kg}$. JIP bulanan tersebut kemudian dibagi menjadi jadwal Induk Produksi dalam mingguan untuk mempermudah proses perhitungan.

Tabel 3.

Peramalan Permintaan Produk Body Scrub Powder 1 kg Bulan Oktober 2018

\begin{tabular}{cc}
\hline Bulan & Jumlah Permintaan $(\mathrm{kg})$ \\
\hline Oktober 2018 & 82 \\
\hline
\end{tabular}

Sumber: Data diolah, 2018

Tabel 4.

JIP Mingguan Bulan Oktober 2018

\begin{tabular}{|c|c|c|c|c|c|}
\hline $\begin{array}{c}\text { Minggu } \\
\text { Produk }\end{array}$ & 1 & 2 & 3 & 4 & Total \\
\hline $\begin{array}{c}\text { Body scrub } \\
\text { powder } 1 \mathrm{~kg}\end{array}$ & 22 & 20 & 20 & 20 & 82 \\
\hline
\end{tabular}

Sumber:Data diolah, 2018

Data JIP mingguan yang telah diketahui kemudian dilakukan langkah analisis MRP. Netting merupakan sebuah proses penentuan kebutuhan bersih dalam MRP yang didapat dari selisih kebutuhan kotor dengan rencana penerimaan dan persediaan di tangan (on hand inventory). Kebutuhan kotor untuk setiap periode diambil dari JIP mingguan yang kemudian dikalikan dengan jumlah 
kebutuhan produk atau bahan baku yang diperlukan untuk setiap kali produksi 1 $\mathrm{kg}$ body scrub powder.

Kebutuhan bersih berisi banyaknya produk serta item atau komponen yang harus diproduksi atau dipesan setiap periode dalam rangka untuk memenuhi kebutuhan produksi. Berikut hasil perhitungan kebutuhan bersih produk dan bahan bakubody scrub powder $1 \mathrm{~kg}$.

Tabel 5.

Hasil Perhitungan Kebutuhan Bersih Produk Body Scrub Powder 1kg

Produk/Bahan Baku Kebutuahan Dalam per Minggu

\begin{tabular}{lcccc} 
& 1 & 2 & 3 & 4 \\
\hline Body Scrub Powder 1 kg & 22 & 20 & 20 & 20 \\
Plastik (lembar) & 0 & 0 & 17 & 20 \\
Label (lembar) & 12 & 40 & 40 & 40 \\
Tepung gandum (gram) & 0 & 2.064 & 3.840 & 3.840 \\
Tepung beras (gram) & 9.806 & 13.460 & 13.460 & 13.460 \\
Scrub (gram) & 248 & 380 & 380 & 380 \\
Ekstrak (gram) & 1.862 & 1.920 & 1.920 & 1.920 \\
Parfume (ml) & 0 & 198 & 380 & 380 \\
Methylparaben (gram) & 32,8 & 48 & 48 & 48 \\
Propylparaben (gram) & 0 & 0 & 5,76 & 9,6 \\
Sumber: Data diam
\end{tabular}

Sumber: Data diolah, 2018

Berdasarkan hasil perhitungan kebutuhan bersih tersebut, selanjutnya akan digunakan sebagai dasar untuk proses lotting atau penentuan jumlah lot untuk setiap kali pembelian atau pemesanan bahan baku.

Metode lot sizing pertama yang akan diuji yaitu metode lot for lotyang fokus dalam meminimumkan biaya simpan, sehingga pembelian hanya dilakukan bertepatan dengan kebutuhan yang diperlukan pada setiap periode (minggu) sehingga, biaya yang timbulkan oleh lot for lot hanya biaya pemesanan. Berikut hasil lot sizing metode lot for lotberserta total biaya persediaan tiap bahan bakunya. 
Berdasarkan tabel 6 dapat dilihat hasil dari perhitungan akhir total biaya persediaan dengan metode lot for lot untuk semua bahan baku berjumlah sebesar Rp 795.000. Setiap bahan baku memiliki biaya berbeda hal ini disebabkan karena jumlah kebutuhan bersih yang berbeda dan mengakibatkan jumlah pemesanan tiap-tiap bahan baku yang berbeda pula. Pemesanan dilakukan untuk memenuhi kebutuhan bersih setiap minggunya sehingga, jumlah pesanan atau ukuran lot harus sama dengan kebutuhan bersih setiap minggunya. Hal tersebut dilakukan untuk menghindari persediaan yang dapat mengakibatkan biaya penyimpanan.

\section{Tabel 6.}

Hasil Akhir Perhitungan Lot Sizing Metode $L F L$ Bulan Oktober 2018

\begin{tabular}{lccccc}
\hline \multirow{2}{*}{ Bahan Baku } & \multicolumn{3}{c}{ Ukuran Lot per Minggu } & Total Biaya \\
\cline { 2 - 5 } & 1 & 2 & 3 & 4 & Persediaan \\
\hline Plastik (lembar) & 0 & 0 & 17 & 20 & Rp 53.000 \\
Label (lembar) & 12 & 40 & 40 & 40 & Rp 106.000 \\
Tepung gandum (gram) & 0 & 2.064 & 3.840 & 3.840 & Rp 79.500 \\
Tepung beras (gram) & 9.806 & 13.460 & 13.460 & 13.460 & Rp 106.000 \\
Scrub (gram) & 248 & 380 & 380 & 380 & Rp 106.000 \\
Ekstrak (gram) & 1.862 & 1.920 & 1.920 & 1.920 & Rp 106.000 \\
Parfume (ml) & 0 & 198 & 380 & 380 & Rp 79.500 \\
Methylparaben (gram) & 32,8 & 48 & 48 & 48 & Rp 106.000 \\
Propylparaben (gram) & 0 & 0 & 5,76 & 9,6 & Rp 53.000 \\
\hline Total Biaya Persediaan & & & & & Rp 795.000 \\
\hline \multicolumn{1}{c}{ Sumber: Data diolah, 2018} & & & &
\end{tabular}

Metodelot sizing yang kedua yang akan diuji yaitu metodepart period balancingyang memiliki cara penentuan ukuran lot dengan menyeimbangkan biaya pesan dan biaya simpan. Metode part period balancingmerupakan metode penyeimbangan part period atau sebagian periode untuk melakukan proses penetapan besar pesanan lot kebutuhan bahan bakupada tiap minggunya atau periode yang berbeda-beda. Metode ini menggunakan pendekatan Economic Part Period (EPP) untuk penentuanbesar lot atau kebutuhan setiap periode. Nilai akumulasi persediaan yang mendekati nilai EPP akan menjadi dasar penentuan 
jumlah besarnya lot untuk masing-masing bahan baku dan dapat meminimumkan biaya persediaan. Berikut hasil metode part period balancingberserta total biaya persediaannya..

Metode lot sizingpart period balancing menghasilkan waktu pemesanan yang berbeda dan jumlah yang berbeda untuk tiap bahan bakunya karena pembelian dilakukan saat bahan baku diperlukan dan pembelian tersebut merupakan akumulasi kebutuhan untuk periode selanjutnya. Pembelian dilakukan dengan mengakumulasi kebutuhan agar memperkecil atau menghemat biaya pemesanan bahan baku.

Tabel 7.

Hasil Akhir Perhitungan Lot Sizing Metode PPB Bulan Oktober 2018

\begin{tabular}{|c|c|c|c|c|c|}
\hline \multirow{2}{*}{ Bahan Baku } & \multicolumn{4}{|c|}{ Ukuran Lot per Minggu } & \multirow{2}{*}{$\begin{array}{l}\text { Total Biaya } \\
\text { Persediaan }\end{array}$} \\
\hline & 1 & 2 & 3 & 4 & \\
\hline Plastik & & & 37 & & Rp 26.511,6 \\
\hline Label & 132 & & & & $\operatorname{Rp} 31.420$ \\
\hline Tepung gandum & & 9.744 & & & $\operatorname{Rp} 28.804$ \\
\hline Tepung beras & 50.186 & & & & Rp 46.690 \\
\hline Scrub & 1.388 & & & & $\operatorname{Rp} 27.457,6$ \\
\hline Ekstrak & 5.702 & & & 1.920 & $\mathrm{Rp} 76.040$ \\
\hline Parfume & & 958 & & & $\mathrm{Rp} 32.200$ \\
\hline Methylparaben & 176,8 & & & & $\operatorname{Rp} 26.868,64$ \\
\hline Propylparaben & & & 15,36 & & $\mathrm{Rp} 26.514,4$ \\
\hline Total Biaya Perse & & & & & Rp 338.911,24 \\
\hline
\end{tabular}

Hasil kedua metode lot sizingyaitu metode lot for lotdan part period balancing memberikan total biaya persediaan yang berbeda setiap bahan baku. Pada setiap bahan baku diharapkan memiliki nilai total biaya persediaan terendah untuk meminimalkan biaya persediaan pada perusahaan sehingga dilakukan perbandingan dengan memilih metode lot sizing yang menghasilkan biaya terendah bagi setiap bahan baku. Hasil dari kedua metode tersebut dibandingkan biayanya dan biaya terendahlah yang kemudian dipilih. 
Pada tabel 8 dapat diketahui perbedaan total biaya persediaan pada kedua metode lot sizing. Metode part period balancing (PPB) menghasilkan nilai total biaya persediaan yang lebih rendah dibandingkan metode lot for lot. Pada penetuan pemilihan metode lot sizing untuk setiap bahan baku dipilih yang memiliki biaya persediaan yang terendah dan pada penelitian ini ternyata semua bahan baku memiliki biaya terendah pada metode PPB.

Tabel 8.

Perbandingan Total Biaya Persediaan Kedua Metode Lot Sizing

\begin{tabular}{|c|c|c|}
\hline \multirow[b]{2}{*}{ Bahan Baku } & \multicolumn{2}{|c|}{ Metode Lot Sizing } \\
\hline & Lot for Lot & $\begin{array}{l}\text { Part Period } \\
\text { Balancing }\end{array}$ \\
\hline Plastik & Rp 53.000 & $\operatorname{Rp} 26.511,6$ \\
\hline Label & Rp 106.000 & $\operatorname{Rp} 31.420$ \\
\hline Tepung gandum & Rp 79.500 & $\operatorname{Rp} 28.804$ \\
\hline Tepung beras & Rp 106.000 & $\mathrm{Rp} 46.690$ \\
\hline Scrub & Rp 106.000 & Rp $27.457,6$ \\
\hline Ekstrak & Rp 106.000 & Rp 76.040 \\
\hline Parfume & $\mathrm{Rp} 79.500$ & $\operatorname{Rp} 32.200$ \\
\hline Methylparaben & Rp 106.000 & $\operatorname{Rp} 26.868,64$ \\
\hline Propylparaben & Rp 53.000 & $\operatorname{Rp} 26.514,4$ \\
\hline $\begin{array}{l}\text { Total Biaya } \\
\text { Persediaan }\end{array}$ & Rp 795.000 & Rp 338.911,24 \\
\hline
\end{tabular}

Sumber: Data diolah, 2018

Offsetting merupakan proses penetuan kapan waktu yang tepat memesan bahan baku dan optimal yang berdasarkan lead time setiap bahan baku. Tabel MRP dibuat berdasarkan hasil lot sizing dan lead time tiap bahan baku. Hasil perhitungan lot sizing menggunakan metode part period balancing dipilih karena menghasilkan biaya terendah bagi tiap bahan baku dengan total biaya persediaan lebih rendah dibandingkan metode lot for lot pada penelitian ini. Berikut hasil akhir penentuan waktu pemesanan atau MRP tiap bahan baku.

\section{Tabel 9.}

Hasil Akhir MRP Bahan Baku Produk Body Scrub Powder 1 kg

\begin{tabular}{lll}
\hline Bahan Baku & Jumlah Pemesanan & Waktu Pemesanan \\
\hline Plastik & 37 lembar & Minggu ke-3 hari ke-4
\end{tabular}




\begin{tabular}{lll} 
Label & 132 lembar & Minggu ke-1 hari ke-3 \\
Tepung gandum & 9.744 gram & Minggu ke-2 hari ke-3 \\
Tepung beras & 50.186 gram & Minggu ke-1 hari ke-3 \\
Scrub & 1.388 gram & Minggu ke-1 hari ke-1 \\
Ekstrak & 5.702 gram; 1.920 gram & Minggu ke-1 hari ke-1; \\
& $958 \mathrm{ml}$ & Minggu ke 4 hari ke-1 \\
Parfume & 176,8 gram & Minggu ke-2 hari ke-1 \\
Methylparaben & 15,36 gram & Minggu ke-1 hari ke-1 \\
Propylparaben & & Minggu ke-3 hari ke-1 \\
\hline Sumber: Data diolah, 2018 & &
\end{tabular}

Pada penelitian ini terjadinya kelebihan persediaan produk dan bahan baku pada produk terjadi akibat tidak adanya perencanaan dalam penentuan kapasitas produksi dan peramalan pada permintaan produk dimasa yang mendatang. Investasi yang tertanam pada persediaan dan mengakibatkan peningkatan biaya persediaan atau terjadinya biaya pemborosan. Terdapatnya permasalahan tersebut ditangga dengan penelitian ini melalui penerapan sistem MRP yang dimulai dari netting, lotting, dan offsetting ke dalam proses produksi.

Pada proses netting diketahui kebutuhan bersih setiap bahan baku pada periode yang terhitung. Jadwal induk produksi terlebih dahulu harus diketahui sebelum netting dilakukan sehingga dapat mengurangi permasalahan kelebihan persediaan dan menentukan kapasitas produksi.

Kebutuhan bersih yang telah diketahui kemudian dilakukan lotting. Proses lotting ini adalah proses penentuan ukuran jumlah pesanan yang optimal setiap bahan baku produk. Proses lotting ini akan memberikan gambaran mengenai berapa jumlah bahan baku yang harus dipesan untuk memenuhi kebutuhan produksi dan tidak terjadi kekurangan maupun kelebihan persediaan. 
Proses akhir sistem MRP dalam penelitian ini yaitu offsetting. Pada proses ini dapat diketahui kapan waktu yang tepat dalam melakukan pemesanan bahan baku dengan pembuatan tabel MRP yang sesuai lead time tiap bahan baku dan juga hasil dari netting dan lotting. Tabel MRP ini akan menjadi gambaran bagi perusahaan terkait kapan waktu untuk pelepasan pesanan atau melakukan pemesanan bahan baku produk yang tepat sehingga, tidak terjadi keterlambatan bahan baku maupun kekurangan bahan baku.

Penelitian ini juga menunjukkan metode peramalan trend projection menghasilkan kesalahan peramalan terkecil (standart error of the estimate) dibandingkan metode moving average dan exponential smoothing serta metode part periode balancing menghasilkan biaya lebih rendah dibandingkan lot for lot. Material Requirement Planning (MRP) dengan metode lot sizing pada penelitian ini belum tentu menghasilkan hasil yang sama pada penelitian di masa akan datang, karena perbedaan data input MRP yang berbeda pada tiap perusahaan.

\section{SIMPULAN DAN SARAN}

Hasil penelitian ini menunjukkan terjadinya kelebihan persediaan produk dan bahan baku pada produk terjadi akibat tidak adanya perencanaan dalam penentuan kapasitas produksi dan peramalan pada permintaan produk dimasa yang mendatang. Investasi yang tertanam pada persediaan dan mengakibatkan peningkatan biaya persediaan atau terjadinya biaya pemborosan. Permasalahan tersebut kemudian dicarikan jalan keluarnya dengan penelitian ini melalui penerapan sistem MRP yang dimulai dari proses netting, lotting, dan offsetting ke dalam proses produksi. 
Pada proses netting dapat diketahui kebutuhan bersih setiap bahan baku pada periode terhitung. Sebelum netting dilakukan terlebih dahulu harus diketahui jadwal induk produksi, sehingga dapat mengurangi permasalahan kelebihan persediaan dan menentukan kapasitas produksi. Netting didapatkan dari selisih antara kebutuhan kotor dengan persediaan di tangan (on hand inventory) masingmasing bahan baku dan melakukan peramalan dengan metode trend projection.

Setelah diketahui kebutuhan bersih kemudian dilakukan lotting. Proses lotting ini adalah proses untuk menentukan ukuran pesanan yang optimal untuk setiap bahan baku produk. Proses lotting ini akan memberikan gambaran bagi perusahaan mengenai berapa jumlah bahan baku yang dipesan agar terpenuhinya kebutuhan produksi dan tidak terjadi kelebihan maupun kekurangan persediaan. Proses lotting atau penentuan besar ukuran pemesanan dalam penelitian ini menggunakan dua metode lot sizing yaitulot for lot dan part period balancing. Pada penelitian ini menunjukkan metode lot sizing part period balancing (PPB) dapat memberikan penghematan biaya.

Proses terakhir sistem MRP penelitian ini yaitu offsetting. Offsetting didasarkan atas metode lot sizing yang telah dipilih yaitu part period balancing (PPB) dengan total biaya persediaan yang lebih minimum dan lead time dari masing-masing bahan baku.Tabel MRP ini akan menjadi uraian bagi perusahaan terkait waktu yang tepat untuk pelepasan pesanan atau melakukan pemesanan bahan baku produk sehingga, tidak terjadi keterlambatan bahan baku maupun kekurangan bahan baku. 
Penelitian ini juga menunjukkan metode peramalan trend projection menghasilkan kesalahan peramalan terkecil (standart error of the estimate) dibandingkan metode moving average dan exponential smoothing serta metode part periode balancing menghasilkan biaya lebih rendah dibandingkan lot for lot.

Saran yang berkaitan dengan penelitian ini yang dapat dijadikan bahan pertimbangan maupun masukan yang bermanfaat bagi CV. Denara Duta Mandiri antara lain sebaiknya perusahaan melakukan perhitungan kebutuhan bersih setiap bahan baku produk body scrub powder $1 \mathrm{~kg}$.

CV. Denara Duta Mandiri sebaiknya melakukan lotting dengan menggunakan metode part period balancing (PPB)dalam menentukan besarnya jumlah pemesanan bahan baku serta perusahaan hendaknya memperhatikan waktu pemesanan setiap bahan baku atau material agar menghindari terjadiya kekurangan bahan baku akibat keterlambatan yang dapat mengakibatkan terhambatnya proses produksi.

Bagi penelitian selanjutnya, penelitian dapat dilakukan di perusahaan lain dengan metode lot sizing yang berbeda, menambah maupun mengganti metode lot sizing lain sebagai perbandingan untuk menunjukkan dan memilih metode mana yang menghasilkan biaya persediaan terendah atau biaya persediaan yang paling efisien.

\section{REFERENSI}

Adeel, S., Zaidi, H., Khan, S. A., \& Dweiri, F. (2012). Implementation of Inventory Management System in a Furniture Company : A Real Case study. International Journal of Engineering and Technology, 2(8), 1457-1474.

Anggriana, K. Z. (2015). Analisis Perencanaan dan Pengendalian Persediaan 
Busbar Berdasarkan Sistem MRP (Material Requirement Planning) di PT. TIS. Jurnal PASTI, 9(3), 320-337.

Aristiyanto, F., Putri, N. T., \& Bronto Adi, A. H. (2016). Usulan Aplikasi Metode Material Requirement Planning (MRP) Dalam Perencanaan Kebutuhan Firebrick PT Semen Padang. Jurnal Optimasi Sistem Industri, 15(2), 217226.

Assauri, S. (2008). Management Produksi dan Operasi. Jakarta.

Ayu, K. G., Septivani, N., Halim, M., Chandra, A., \& Setiawan, F. N. (2013). Perencanaan Produksi dan Material Produk Klem, Brake dan Plat di PT "XYZ". INASEA Journal, 14(9), 102-114.

Chandradevi, A., \& Puspitasari, N. B. (2016). Penerapan Material Requirement Planning ( MRP ) dengan Mempertimbangkan Lot Sizing dalam Pengendalian Bahan. Performa, 15(1), 77-86.

Chandraju, S., Raviprasad, B., \& Kumar, C. S. C. (2012). Implementation of System Application Product ( SAP ) Materials Management ( MM-Module ) for Material requirement planning ( MRP ) in Sugar Industry. International of Scientific and Research Publications, 2(9), 1-5.

Davis, M. M., \& Haineke, J. (2005). Operation Management Integrating Manufacturing \& Services (5th ed). McGraw Hill International Edition.

Dinesh, E. D., Arun, A. P., \& Pranav, R. (2014). Material Requirement Planning for Automobile Service Plant. International Journal of Innovative Research in Science, Engineering and Technology, 3(3), 1171-1175.

Fajar S, R., \& Wiwi, U. (2014). Penerapan Material Requirement Planning (MRP) dalam Perencanaan Persediaan Bahan Baku Produk Botol DK 8211 B di PT. Rexam Packaging Indonesia. JTM, 3(1), 71-79.

Gharakhani, D. (2011). Optimization of Material Requirement Planning by Goal Programming Model. Asian Journal of Management Research, 2(1), 297317.

Hafiz, U., \& Parveen, S. (2010). A Literature Review on Inventory Lot Sizing 
Shinta Monica dan Putu Yudi Setiawan, Analisis Material Requirement...

Problem. Global Journal of Researches in Engineering, 10(5), 29-44.

Haizer, J., \& Barry, R. (2005). Manajemen Operasi (Edisi Tujuh). Jakarta: Salemba Empat.

Haizer, J., \& Barry, R. (2015). Manajemen Operasi: Manajemen Keberlangsungan dan Rantai Pasokan (Edisi 11). Jakarta: Salemba Empat.

Handoko, T. H. (2000). Management Personalia dan Sumberdaya Manusia (Edisi 2). Yogyakarta: BPFE-Yogyakarta.

Herjanto, E. (1999). Manajemen Produksi \& Operasi (Edisi Kedua). Jakarta: PT. Grasindo.

Herjanto, E. (2008). Manajemen Operasi (Edisi Ketiga). Jakarta: PT. Grasindo.

Iasya, A., \& Handayati, Y. (2015). Material Requirement Planning Analysis In Micro, Small and Medium Enterprise. Journal of Business and Management, $4(3), 317-329$.

Imetieg, A. A., \& Lutovac, M. (2015). Project Scheduling Method With Time Using MRP System - A Case Study: Construction Project In Libya. The European Journal of Applied Economics, 12(1), 58-66. https://doi.org/10.5937/EJAE12-7815

Joko, S. (2004). Manajemen Produksi dan Operasi (Suatu Pengantar) (Edisi Kedu). Malang: UMM.

Jonsson, P., \& Mattsson, S.-A. (2016). Advanced Material Requirement Planning Performance: a Contextual Examination and Research Agenda. International Journal of Physical Distribution \& Logistic, 46(9), 836-858.

Kamarul, I. (2009). Manajemen Persediaan. Jember: Fakultas Ekonomi Universitas Jember.

Krajewski, L. J., Malhotra, M. J., \& Ritzman, L. P. (2016). OperationManagement Processes and Supply Chains (Eleventh Edition). United States: Pearson Education Limited. 
Kumar, A. S., \& Suresh, N. (2008). Production and Operations Management: with Skill Development, Caselets, and Cases. New Delhi: New Age International (P) Limited, Publisers.

Kusuma, H. (2009). Manajemen Produksi: Perencanaan dan Pengendalian Produksi (Edisi 4). Yogyakarta: Penerbit Andi.

Limbong, I., Tarore, H., Tjakra, J., \& Walangitan, D. R. O. (2013). Manajemen Pengadaan Material Bangunan Dengan Menggunakan Metode MRP (Material Requirement Planning) Studi Kasus: Revitalisasi Gedung Kantor BPS Propinsi Sulawesi Utara. Jurnal Sipil Statik, 1(6), 421-429.

Nasution, A. H., \& Prasetyawan, Y. (2008). Perencanaan Pengendalian Produksi. Yogyakarta: Graha Ilmu.

Olaore, R. A., \& Olayanju, M. (2013). Purchasing Functions and MRP in Foodservice Firms. European Journal of Business and Management, 5(13), 107-113.

Panizzolo, R., \& Garengo, P. (2013). Using Theory of Constraints to Control Manufacturing System: A Conceptual Model. Industrial Engineering and Management, 3(3), 1-9.

Rangkuti, F. (2007). Manajemen Persediaan: Aplikasi di Bidang Bisnis (Edisi 2). Jakarta: PT. Raja Grafindo Persada.

Riyanto, B. (2012). Dasar-dasar Pembelanjaan Perusahaan. Yogyakarta: BPFE.

Santin, K., Cardoso, B. M., Pedro Domingos, A., Ana Rita, T. T., \& Santos Guimaraes, S. (2015). MRP Implementation On Supply Management Process: A Brazilian Furniture Industry Case Study. European Journal of Business and Social Sciences, 4(01), 158-173.

Sarkar, A., Das, D., Chakraborty, S., \& Biswas, N. (2013). A Simple Case Study of Material Requirement Planning A Simple Case Study of Material Requirement Planning. IOSR Journal of Mechanical and Civil Engineering, 9(5), 58-64. https://doi.org/10.9790/1684-0955864

Subagyo, P., Asri, M., \& Handoko, T. H. (2013). Dasar-dasar Operation 
Research (Edisi 2). Yogyakarta: BPFE-Yogyakarta.

Sungkono, M. A., \& Sulistiyowati, W. (2016). Perencanaan dan Pengendalian Bahan Baku Untuk Meningkatkan Efisiensi Produksi Dengan Metode Material Requirement Planning dan Analytical Hierarchy Process di PT. XYZ. Spektrum Industri, 14(1), 11-24.

Suparno. (2017). Analisis Penerapan Material Requirement Planning (MRP) Dengan Mempertimbangkan Lot Sizing. Nusantara Journal of Computers and Its Applications, 2(2), 71-81.

Theresia, P., \& Salomon, L. L. (2015). Usulan Penerapan Material Requirement Planning (MRP) Untuk Pengendalian Persediaan Bahan Baku Produk ANT INK (Studi Kasus: CV. Sinar Mutiara). Jurnal Kajian Teknologi, 11(1), 4354.

Torunoglu, Y. E., Kirli Akin, H., \& Guler, N. (2017). Material Requirement Planning in a Briquette Factory. International Advanced Research and Enginering Journal, 1(1), 21-25.

Wahyuni, A., \& Syaichu, A. (2015). Perencanaan Persediaan Bahan Baku Dengan Menggunakan Metode Material Requirement Planning (MRP) Produk Kacang Shanghai Pada Perusahaan Gangsar Ngunut-Tulungangung. Spektrum Industri, 13(2), 141-156. 